\title{
TẮC HẸP AVF TRONG CHẠY THẬN NHÂN TẠO: KẾT QUẢ BƯỚC ĐẦU ĐIỀU TRI BĂNG CAN THIỆP NỘI MẠCH
}

Phạm Minh Ánh*, Huỳnh Thanh Sơn*, Nguyễn Minh Tấn**,

\section{I. ĐẶT VẤN ĐỀ}

Hiện nay, tỉ lệ bệnh nhân mắc bệnh thận mạn ngày càng gia tăng. Ước tính Việt Nam hiện có khoảng 5 triệu người bị suy thận, trong đó khoảng 26.000 người suy thận mạn giai đoạn cuối. Ngoài ra, mỗi năm có thêm gần 8.000 ca bệnh mới. Do đó, bệnh thận mạn giai đoạn cuối và điều trị thay thế thận hiện nay đã trở thành một vấn đề cấp thiết có tính toàn cầu. Điều trị thay thế thận bao gồm ghép thận, chạy thận nhân tạo và lọc màng bụng định kỳ, trong đó, chạy thận nhân tạo là phương pháp được sử dụng nhiều nhất. Để chạy thận lâu dài, bệnh nhân thường được phẫu thuật tạo cầu nối động - tĩnh mạch tự thân hay còn gọi là cầu nối AVF. Cầu nối AVF là một trong những vấn đề sống còn đối với bệnh nhân có bệnh thận giai đoạn cuối. Hẹp tắc tĩnh mạch đường về của cầu nối là vấn đề thường gặp nhất, làm giảm hiệu quả chạy thận và chất lượng cuộc sống của bệnh nhân. Phẫu thuật và can thiệp nội mạch là hai phương pháp có thể điều trị bệnh lý này. Phương pháp nào là tối ưu hiện vẫn chưa được thống nhất. Tuy nhiên, đối với trường hợp tắc hẹp tĩnh mạch trung tâm (tĩnh mạch dưới đòn, tĩnh mạch thân tay đầu) can thiệp nội mạch tỏ ra có ưu thế. Tại Việt Nam, kĩ thuật can thiệp nội mạch điều trị tắc hẹp cầu nối $\mathrm{AVF}$ là kĩ thuật mới, chưa có nhiều công trình nghiên cứu báo cáo. Do đó, chúng tôi thực hiện nghiên cứu nhằm đánh giá kết quả ban đầu của phương pháp điều trị này.
Nguyễn Thành Hung**, Luu Văn Tý***

\section{II. ĐỐI TƯợNG VÀ PHƯƠNG PHÁP NGHIÊN CÚU}

\section{1. Đối tượng nghiên cứu}

Bệnh nhân suy thận mạn giai đoạn cuối đang chạy thận định kỳ bị hẹp tắc cầu nối AVF và được điều trị tại khoa Phẫu thuật Mạch máu Bệnh viện Chợ Rẫy trong năm 2017. Tiêu chuẩn chọn mẫu: bệnh nhân được điều trị can thiệp nội mạch. Tiêu chuẩn loại trừ: bệnh nhân được phẫu thuật mổ mở

\subsection{Phương pháp nghiên cứu}

Nghiên cứu hồi cứu, được thực hiện tại khoa Phẫu thuật Mạch máu bệnh viện Chợ Rẫy từ tháng $1 / 2017-12 / 2017^{*}$

Trước can thiệp: bệnh nhân được đánh giá lâm sàng, siêu âm hoặc chụp DSA đánh giá tổn thương.

Trong lúc can thiệp: bệnh nhân được chọc kim động mạch hoặc tĩnh mạch, sau đó luồn dây dẫn trong lòng mạch. Can thiệp tại vị trí tổn thương bằng nong bóng hoặc kết hợp đặt stent. Sau đó chụp kiểm tra đánh giá kết quả. Cuối cùng rút dụng cụ và đè ép hoặc khâu lại vị trí chọc kim.

Sau can thiệp đánh giá lại tình trạng lâm sàng và những thay đổi về áp lực tĩnh mạch trong lúc chạy thận.

\footnotetext{
* Khoa Phẫu thuật Mạch máu bệnh viện Chợ Rãay Ngườ chịu trách nhiệm khoa học: Ths Huỳnh Thanh Sơn Ngày nhận bài: 15/07/2018 - Ngày Cho Phép Đăng: 20/07/2018 Phản Biện Khoa họ: PGS.TS. Đặng Ngocc Hùng GS.TS. Lê Ngọ Thành
} 


\section{KẾT QUẢ}

\section{1. Đặc điểm chung của mẫu nghiên cứu}

Mẫu nghiên cứu có 16 bệnh nhân (6 nam, tỉ lệ nam/nữ là $6 / 10$, độ tuổi trung bình là 62,2 tuổi). Các bệnh nhân nhập viện với lý do: phù tay (56\%), lưu lượng thấp (19\%), đau tay (13\%), tắc $\mathrm{AVF}$ và lơ mơ có 1 trường hợp $(6 \%)$. Thời gian chạy thận trước đó qua AVF trung bình 39 tháng, trong đó có 5 trường hợp chưa chạy được lần nào đã phát hiện tắc (0 tháng), có 1 trường hợp đã chạy thận được trên 10 năm (128 tháng). Trong 16 bệnh nhân có 5 trường hợp đã được phát hiện hẹp tắc trước đó và đã được can thiệp nhưng tái hẹp (chiếm 31\%).

Có 3 bệnh nhân được làm cầu nối AVF ở cổ tay $(19 \%), 3$ cầu nối ở tĩnh mạch nền khuỷu tay (19\%), còn lại 13 bệnh nhân ở tĩnh mạch đầu khuỷu tay (63\%). Đánh giá lâm sàng trước can thiệp: đau tay $(94 \%)$, phù tay $(75 \%)$, thay đổi màu sắc $\mathrm{da}(13 \%)$, loét $\mathrm{da}$ (6\%), mất thrill (19\%).

Các trường hợp hẹp tắc AVF phần lớn đều được đặt kim chạy thận tạm thời: ở tĩnh mạch cảnh (17\%), tĩnh mạch đùi $(25 \%)$, lấy máu ra ở $\mathrm{AVF}$, trả máu về ở tĩnh mạch đùi (25\%). Chỉ có 4 trường hợp (33\%) vẫn tiếp tục dùng đường $\mathrm{AVF}$ để chạy thận nhân tạo.

Tất cả các bệnh nhân đều được chẩn đoán trước mổ bằng các phương tiện hình ảnh học như siêu âm doppler, CT scan hay DSA. Sau đó được đánh giá lại tổn thương chính xác ngay trước khi can thiệp.

Bảng 1. Tổn thuoong mạch máu trên DSA

\begin{tabular}{|l|c|c|}
\hline \multicolumn{1}{|c|}{ Đặc điểm trên DSA } & $\mathbf{n}$ & Tỉ lệ (\%) \\
\hline \multicolumn{1}{|c|}{ Vị trí hẹp } & & \\
\hline Miệng nối và đoạn tĩnh mạch bản lề & 3 & 18,8 \\
\hline Tĩnh mạch dẫn lưu ngoại biên & 7 & 42,8 \\
\hline Cung tĩnh mạch đầu & 1 & 6,3 \\
\hline TM thân tay đầu & 2 & 12,5 \\
\hline TM nền & 2 & 12,5 \\
\hline TM cánh tay & 1 & 6,3 \\
\hline & & \\
\hline $\mathbf{7 0 \%}$ Mức độ hẹp & 1 & 6,3 \\
\hline $\mathbf{7 5 \%}$ & 1 & 6,3 \\
\hline $\mathbf{8 0 \%}$ & 3 & 18,8 \\
\hline $\mathbf{9 0 \%}$ & 4 & 25 \\
\hline $\mathbf{9 5 \%}$ & 2 & 12,5 \\
\hline $\mathbf{1 0 0 \%}$ & 5 & 31,3 \\
\hline
\end{tabular}

\subsection{Kỹ thuật can thiệp}

Trong 16 trường hợp can thiệp, có 4 lần chọc kim ở động mạch cánh tay (25\%), 9 lần chọc kim ở tĩnh mạch đầu (56\%), còn lại $19 \%$ chọc kim vào tĩnh mạch nền, chính là những bệnh nhân được làm cầu nối từ động mạch cánh tay vào tĩnh mạch nền. Một trường hợp can thiệp thất bại do không đi dây dẫn qua vị trí tổn thương được, chiếm $6 \%$. Còn 15 bệnh nhân còn lại đều đi dây dẫn thành công và được tiến hành nong bóng. 


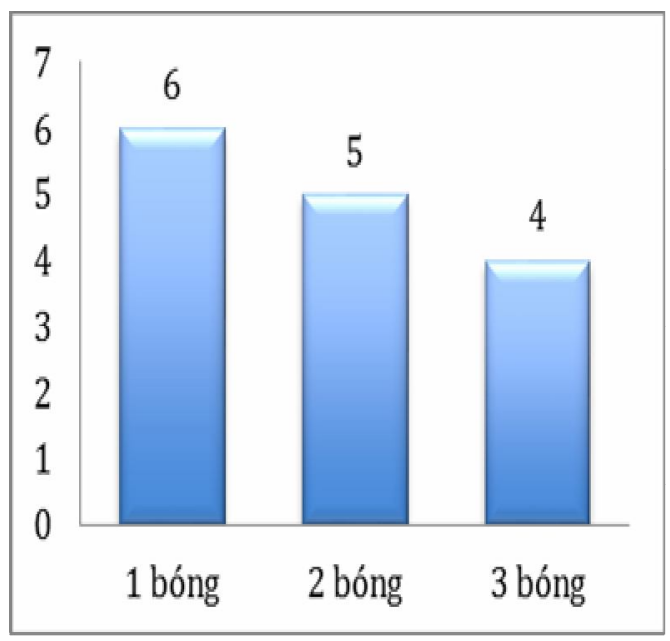

\section{Biểu đồ. Số luọng bóng sử dụng trong 1 lần can thiệp}

Có tất cả 28 bóng đã được dùng, với đường kính trung bình là $9,5 \mathrm{~mm}$, chiều dài trung bình là 69,3mm. Một bệnh nhân sau khi nong bóng, tĩnh mạch trung tâm còn hẹp nặng, nên đã được đặt stent kích thước $8 \times 60 \mathrm{~mm}$. Thời gian can thiệp trung bình là $118 \pm 47$ phút.

\subsection{Kết quả}

Đánh giá sau can thiệp: thành công về kỹ thuật đạt $81 \%$ (kết thúc can thiệp thành công và hẹp tồn lưu sau can thiệp $\leq 30 \%$ ); không có trường hợp nào xảy ra biến chứng; về mặt lâm

\section{Một số hình ảnh trong lúc can thiệp.}

*Trường hợp 1 :

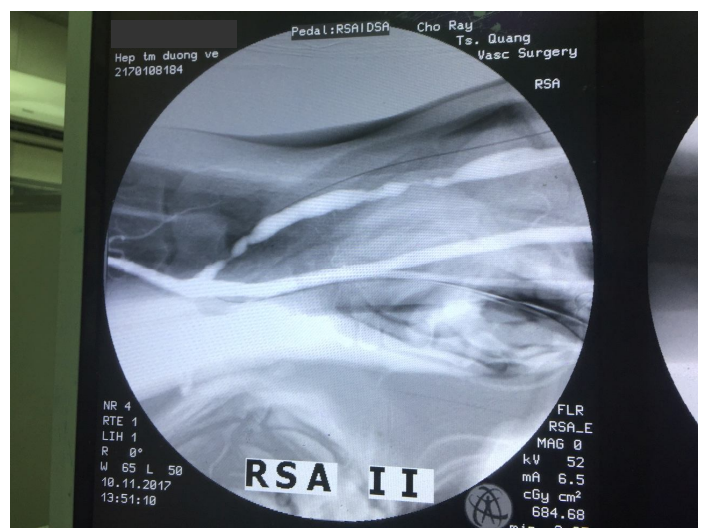

Hình 3.1. Hẹp rải rác tù̀ miệng nối đến thân tĩnh mach đầu sàng: $75 \%$ giảm đau tay, $56 \%$ giảm phù tay, $94 \%$ có mạch hạ lưu và cầu nối còn rù tốt; thời gian nằm viện sau can thiệp trung bình là $2,9 \pm$ 2,8 ngày (sớm nhất 1 ngày, lâu nhất 13 ngày).

Các bệnh nhân được chạy thận qua AVF mà không có đường tạm thời có sự thay đổi về áp lực tĩnh mạch trước và sau khi can thiệp. Cụ thể: áp lực tĩnh mạch trung bình máu về trước can thiệp của 4 bệnh nhân này là $144 \mathrm{mmHg}$, tăng lên $166 \mathrm{mmHg}$ sau can thiệp. Tuy nhiên sự thay đổi này không có ý nghĩa thống kê.

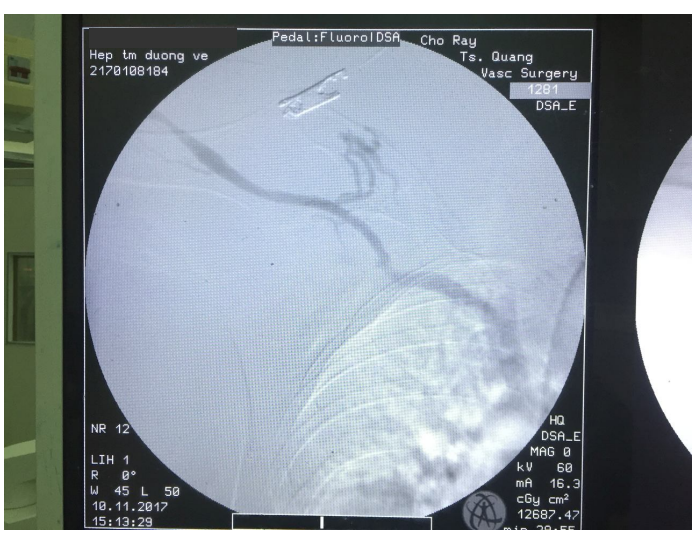

Hình 3.2. Hẹp cung tĩnh mach đầu 


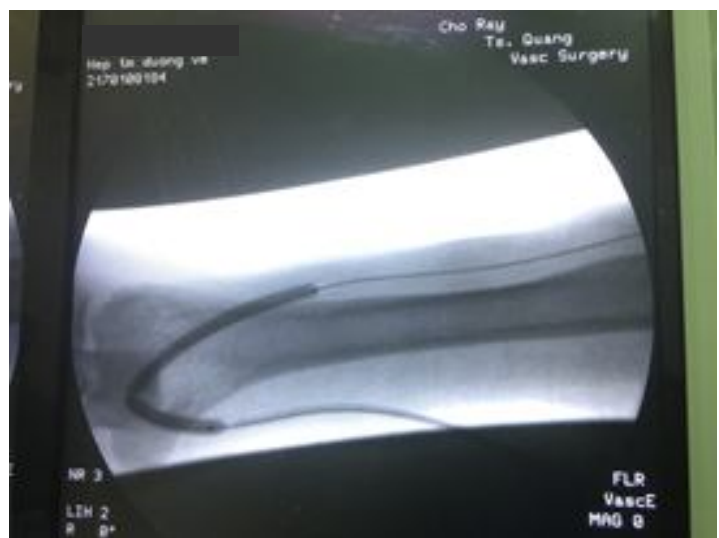

Hình 3.3. Nong miệng nối và tĩnh mach bản lề

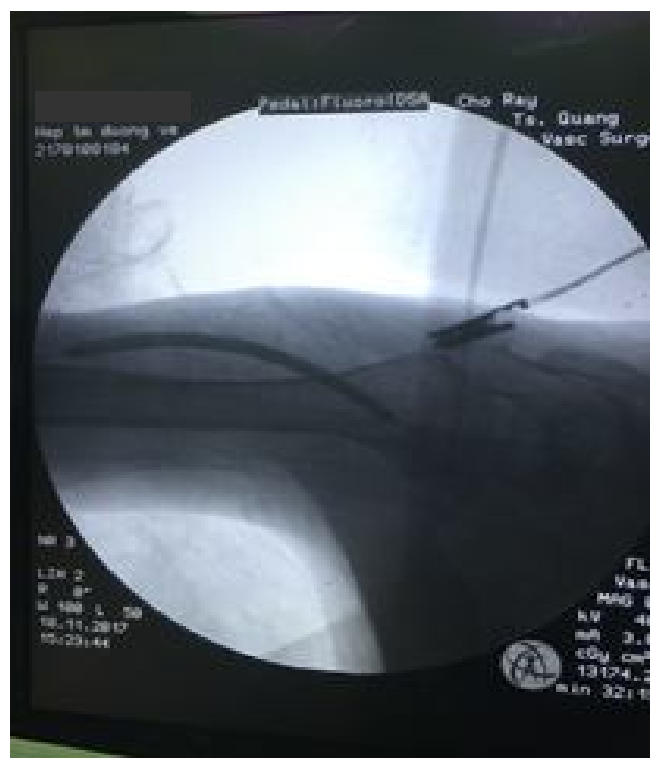

Hình 3.5. Nong cung tĩnh mạch đầu

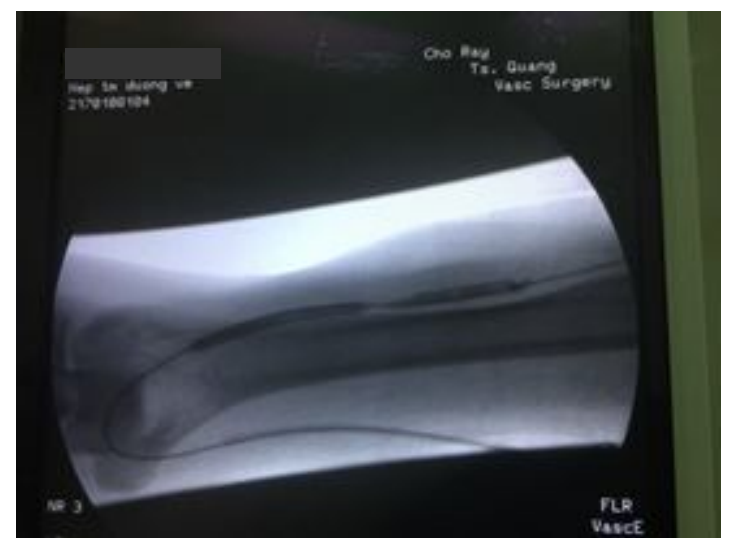

Hình 3.4. Nong tĩnh mạch đầu

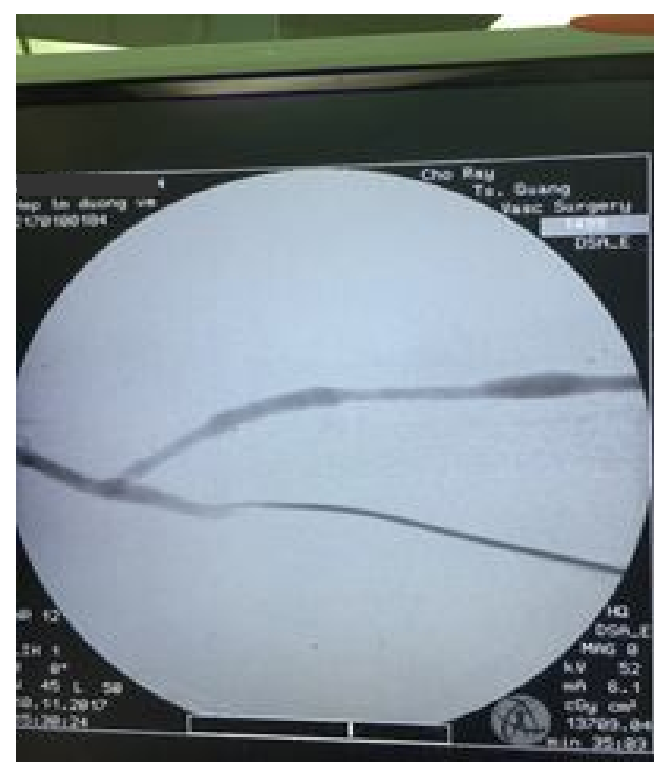

Hình 3.6. Chup kiểm tra, tĩnh mạch đầu nở tốt, hẹp tồn luu $<30 \%$

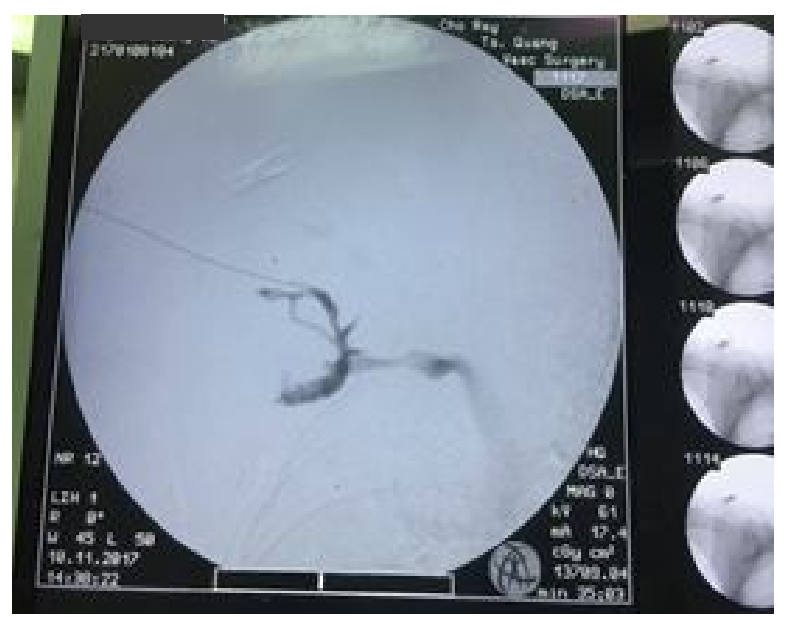

Hình 3.7. Chup kiểm tra, cung tĩnh mạch đầu nở tốt 
Trường hợp 2:

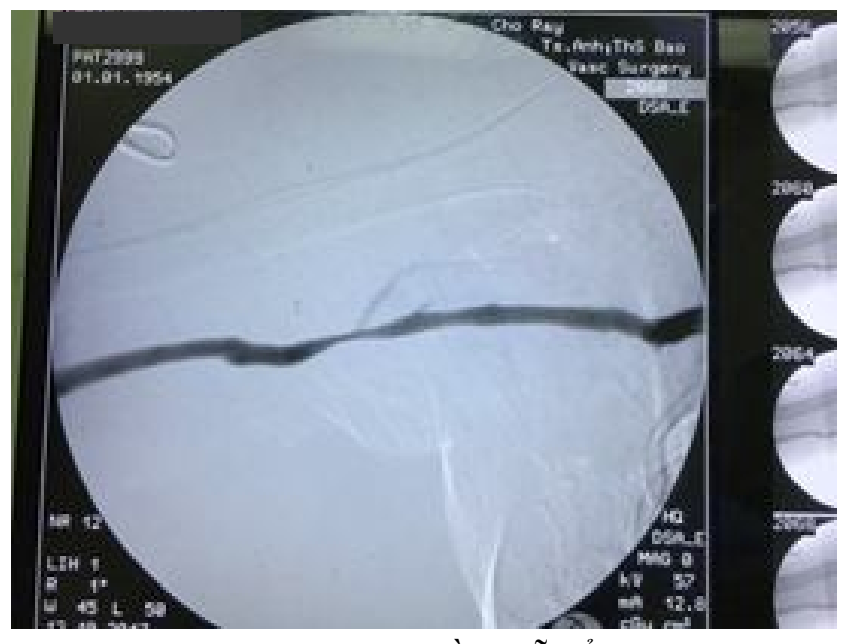

Hình 3.8. Hẹp tĩnh mach nền chỗ đổ vào tĩnh mach cánh tay

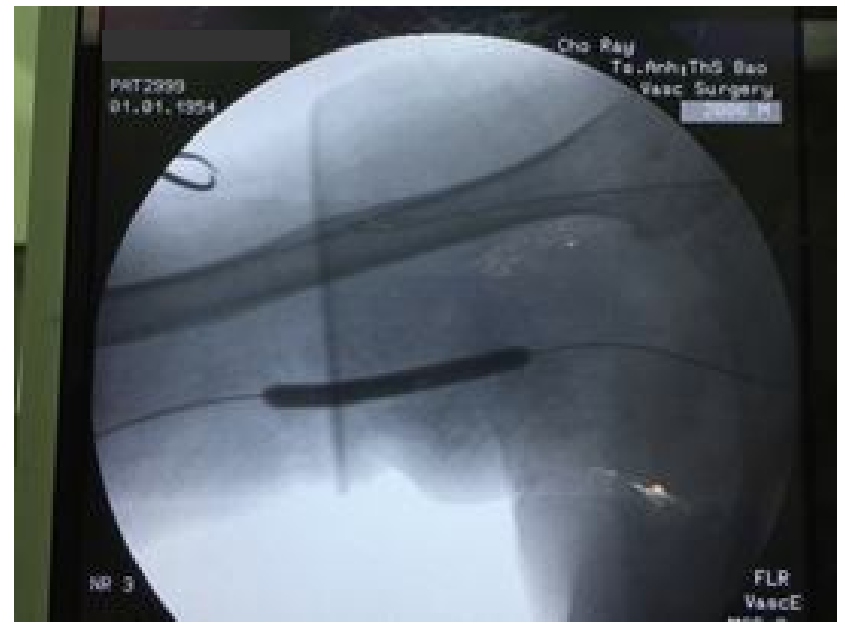

Hình 3.9. Nong bóng tĩnh mạch nền

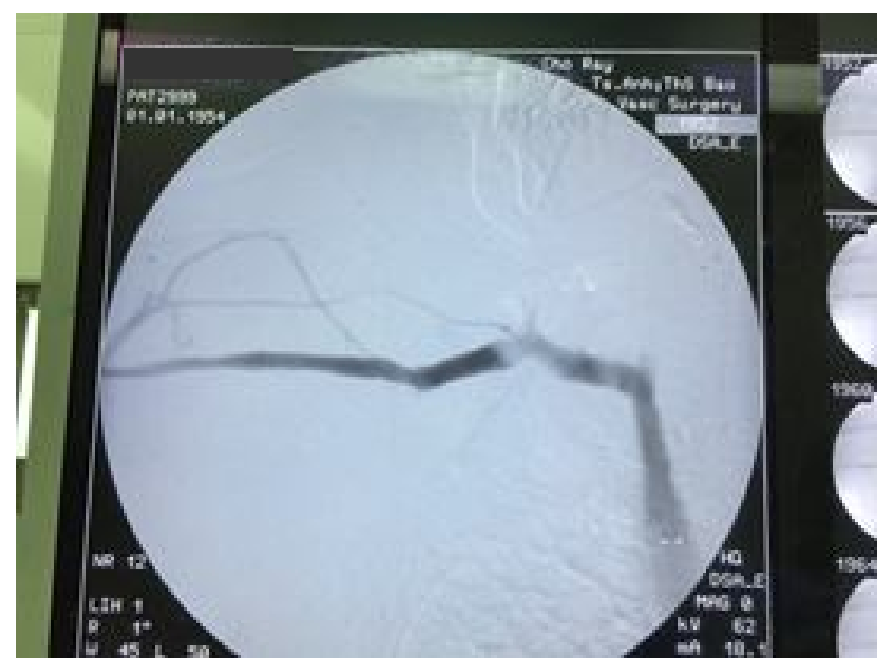

Hình 3.10. Chup kiểm tra tĩnh mạch nở tốt

\section{BÀN LUẬN}

Tổn thương hẹp mạch máu trong các cầu nối AVF có thể xảy ra ở bất kỳ vị trí nào, tuy nhiên hẹp tĩnh mạch thường gặp hơn động mạch. Một số vị trí tĩnh mạch có nguy cơ hẹp rất cao, đặc trưng bởi các dòng chảy xoáy, như các chỗ hợp lưu, các van tĩnh mạch và các điểm gập góc (swing-point). Chúng tôi ghi nhận được các vị trí tắc hẹp của cầu nối AVF gồm: tại miệng nối và đoạn tĩnh mạch bản lề $(18,8 \%)$, tại đoạn tĩnh mạch dẫn lưu ngoại biên
$(42,8 \%)$, cung tĩnh mạch đầu $(6,3 \%)$, tại thân tay đầu $(12,5 \%)$, tĩnh mạch nền $(12,5 \%)$ và tĩnh mạch cánh tay $(6,3 \%)$. Theo tác giả Gerald $\mathrm{A}$ Beathard trong một báo cáo tổng hợp năm 2017, trong các trường hợp làm $\mathrm{AVF}$ bằng tĩnh mạch tự thân, các vị trí hẹp lần lượt có tỉ lệ là: động mạch đến $(6 \%)$, miệng nối và đoạn tĩnh mạch bản lề (55\%), đoạn tĩnh mạch hiệu dụng (29\%), đoạn tĩnh mạch dẫn lưu ngoại biên (10\%) [2]. Còn theo tác giả Arshdeep Sidhu, hẹp động mạch đến chiếm $2 \%$, miệng nối và 
tĩnh mạch bản lề chiếm 27,6\%, tĩnh mạch dẫn lưu ngoại biên $34,7 \%$, cung tĩnh mạch đầu 26,5\%, tĩnh mạch trung tâm 9,2\% [4]].

Đoạn tĩnh mạch gập góc (swing-point) là một cấu trúc đặc biệt của cầu nối $\mathrm{AVF}$, bao gồm: miệng nối và tĩnh mạch bản lề trong các cầu nối động mạch quay-tĩnh mạch đầu ở cổ tay, cung tĩnh mạch đầu ở các cầu nối động mạch cánh tay-tĩnh mạch đầu, và góc hẹp do chuyển vị nông hóa tĩnh mạch nền trong các cầu nối động mạch cánh tay - tĩnh mạch nền. Theo một nghiên cứu năm 2017, các điểm swing-point chiếm đến $35,4 \%$ ở cầu nối động mạch cánh tay-tĩnh mạch đầu, $33,9 \%$ ở cầu nối động mạch quay-tĩnh mạch đầu, 30,7\% động mạch cánh tay-tĩnh mạch nền [1].

Hẹp quanh miệng nối được định nghĩa là đoạn tĩnh mạch từ miệng nối đến $3-4 \mathrm{~cm}$ đầu tiên của tĩnh mạch dẫn lưu, có 3 dạng có thể gặp là chỉ liên quan đến miệng nối, chỉ liên quan đến tĩnh mạch bản lề, và kết hợp cả 2 dạng trên. Dạng tổn thương này thường gây triệu chứng đầu tiên là giảm áp lực máu động mạch khi chạy thận. Nghiên cứu của chúng tôi cũng có tỉ lệ tương tự các nghiên cứu trên thế giới.

Những trường hợp làm cầu nối động mạch cánh tay-tĩnh mạch nền, cần phải làm nông hóa tĩnh mạch nền để chạy thận nhân tạo. Điều này tạo ra góc chuyển vị khi mang tĩnh mạch ở sâu lên trên bề mặt da và đính vào mặt trước cánh tay. Tỉ lệ hẹp ở vị trí này khá cao, chiếm 74\% trong số các trường hợp hẹp AVF ở cầu nối động mạch cánh tay-tĩnh mạch nền [1]]. Tương tự trường hợp này là các cầu nối động mạch cánh tay vào tĩnh mạch cánh tay, chiếm khoảng $50 \%$ [1]].
Cung tĩnh mạch đầu là một cấu trúc mạch máu đặc biệt cả về giải phẫu lẫn huyết động. Tĩnh mạch đầu ở cánh tay đi trong rãnh delta ngực, sau đó chạy sâu xuống dưới, ngay sau xương đòn, để đổ vào tĩnh mạch nách. Tĩnh mạch đầu đoạn này gọi là cung tĩnh mạch đầu, khi chạy qua lớp cân ngực-đòn sẽ tạo thành góc $90^{\circ}$. Chính điểm swing-point này vừa gập góc, vừa ngăn cản tĩnh mạch nở ra do tăng lưu lượng máu về. Hẹp tại cung tĩnh mạch đầu chiếm khoảng 15-18\% các trường hợp [1], cao hơn so với nghiên cứu của chúng tôi $(6,3 \%)$, và thường gặp ở cầu nối động mạch cánh tay-tĩnh mạch đầu hơn là cầu nối động mạch quay-tĩnh mạch đầu.

Đối với tĩnh mạch trung tâm, tỉ lệ hẹp thực sự không được biết rõ, vì chúng ta chỉ phát hiện hẹp khi có triệu chứng, trong khi nhiều bằng chứng hiện nay chỉ ra rằng rất nhiều trường hợp hẹp chưa gây triệu chứng [1]. Hẹp tĩnh mạch trung tâm có thể xảy ra ở bất kỳ vị trí nào, trong đó hẹp chỗ nối cung tĩnh mạch đầu-tĩnh mạch dưới đòn chiếm 38\%, tĩnh mạch thân tay đầu chiếm $29 \%$, tĩnh mạch dưới đòn chiếm $24 \%$, và tĩnh mạch chủ trên chiếm 9\% [1]]. Tĩnh mạch dưới đòn rất dễ bị tổn thương khi nó đi qua khớp nối giữa xương đòn và xương sườn 1.

Đánh giá kết quả thành công về mặt kỹ thuật, nghiên cứu của chúng tôi đạt $81 \%$, trong đó có 2 trường hợp còn hẹp tồn lưu $>30 \%, 1$ trường hợp tắc hoàn toàn không đi được dây dẫn qua chỗ tổn thương nên ngưng thủ thuật, tỉ lệ biến chứng là $0 \%$. So sánh với các nghiên cứu khác: tỉ lệ thành công của tác giả Sidhu là $78 \%$, tỉ lệ biến chứng là 2,6\% [4]; của tác giả Beathard là $95 \%$, tỉ lệ lưu thông thì đầu sau 3 tháng là $92 \%$, 
sau 6 tháng là $57-77 \%$, sau 1 năm là 35-69\% [1]; của tác giả Masahiro Horikawa là 70-90\%, tỉ lệ lưu thông thì đầu sau 6 tháng là 23-63\% [3] .

Tắc hẹp tĩnh mạch đường về của cầu nối AVF là một bệnh lý có khả năng tái phát cao. Theo nghiên cứu của chúng tôi, có $31 \%$ bệnh nhân đã từng được can thiệp tiều trị trước đó nhưng tái hẹp. Trong một nghiên cứu của tác giả Arshdeep Sidhu năm 2016, cũng có 51\% bệnh nhân bị tái hẹp, trong số đó $35,7 \%$ làm cầu nối ở cổ tay, $64,3 \%$ làm cầu nối ở khuỷu tay [4]. Theo tác giả Beathard, tỉ lệ tái hẹp sau can thiệp cao là do tính đàn hồi của tĩnh mạch dẫn lưu. Điều này có thể xảy ra nhanh hay chậm tùy vào tính đàn hồi của tĩnh mạch mỗi bệnh nhân, có thể từ vài phút đến vài giờ, hoặc có thể vài năm sau. Can thiệp lặp lại nhiều lần là điều hiển nhiên để đảm bảo lưu lượng máu chạy thận. Thời gian trung bình lặp lại can thiệp đối với $\mathrm{AVF}$ tự thân là 11,2 tháng [2].

\section{KẾT LUẬN}

Qua các kết quả nghiên cứu của chúng tôi và của các tác giả ngoài nước, chúng tôi thấy rằng phương pháp can thiệp nội mạch điều trị tắc hẹp cầu nối $\mathrm{AVF}$ trong chạy thận nhân tạo cho kết quả khá tốt, tỉ lệ thành công về kỹ thuật cao, tỉ lệ biến chứng thấp, thời gian thực hiện thủ thuật và thời gian nằm viện sau can thiệp ngắn. Đặc biệt phương pháp này áp dụng tốt, an toàn cho những trường hợp lớn tuổi, vốn có nhiều bệnh lý phối hợp, là yếu tố nguy cơ của những cuộc mổ lớn, kéo dài. Đối với bệnh nhân suy thận mạn giai đoạn cuối, cầu nối $\mathrm{AVF}$ chính là tính mạng bệnh nhân. Do đó, cố gắng bảo tồn những đường chạy thận với những thủ thuật ít xâm lấn nhất đang là mục tiêu đề ra của những phẫu thuật viên mạch máu trên toàn thế giới. Với điều kiện y tế Việt Nam hiện nay, trang thiết bị phòng mổ cũng như các dụng cụ can thiệp ngày càng tiên tiến, tiệm cận với điều kiện của thế giới, sự chuẩn bị bệnh nhân trước mổ ngày càng tốt hơn, đội ngũ y bác sĩ được đưa đi đào tạo nước ngoài bài bản về kỹ thuật can thiệp nội mạch, chúng tôi tin rằng có thể áp dụng tốt kỹ thuật này ở Việt Nam, mang lại nhiều lợi ích cho bệnh nhân.

\section{TÀI LIỆU THAM KHẢO}

1. Beathard G. A., Cull D. L. \& Collins K. A. (2017), "Failure of the mature hemodialysis arteriovenous fistula", from https://www.uptodate.com/contents/failure-ofthe-mature-hemodial...

rch_result\&selectedTitle $=3 \sim 150 \&$ usage_type $=$ default\&display_rank $=3$.

2. Beathard G. A., Schwab S. J., Cull D. L. \& Collins K. A. (2017), "Endovascular intervention for the treatment of stenosis in the arteriovenous access", from https://www.uptodate.com/contents/endovascul ar-intervention-for-th...is-in-the-arteriovenousaccess $/$ print?topicRef $=1957 \&$ source $=$ see_link.

3 .Horikawa M. \& Quencer K. B. (2017), "Central venous interventions", Techniques in Vascular \& Interventional Radiology, 20(1), 48-57.

4. Sidhu A., Tan K. T., Noel-Lamy M., Simons M. E. \& Rajan D. K. (2016), "Does Technical Success of Angioplasty in Dysfunctional Hemodialysis Accesses Correlate with Access Patency?", Cardiovascular and interventional radiology, 39(10), 1400-1406. 